Citation: Muhonen, T., \& Torkelson, E. (2008). Collective and individualistic coping with stress at work. Psychological reports, 102(2), 450-458.

\title{
COLLECTIVE AND INDIVIDUALISTIC COPING WITH STRESS AT WORK ${ }^{1,2}$
}

\author{
TUIJA MUHONEN AND EVA TORKELSON \\ Malmö University \\ Sweden \\ Lund University \\ Sweden
}

\begin{abstract}
Summary.-In the present study coping was viewed as both an individualistic and a collective phenomenon, and the investigation assessed how use of collective and individualistic coping strategies was related to gender and organizational level. These strategies were measured by responses to Swedish versions of the Strategic Approach to Coping Scale and the COPE scale. Data were collected by means of an Internet-based questionnaire completed by 950 female $(n=502)$ and male $(n=448)$ employees at both the managerial $(n=171)$ and nonmanagerial $(n$ $=764$ ) levels working in customer service in a Swedish telecom company. The mean age of the participants was 47 years $(S D=9.7)$. The results showed that women more often used collective strategies, but so too did managers, both women and men. No interaction effects between gender and organizational level were found. Separate analyses for women and men showed similar patterns, indicating the importance of organizational level for coping. Additional studies are needed in order to investigate the meaning of collective coping at work for women and men at different organizational levels.
\end{abstract}

Work-related stress was the second most frequently reported health problem according to the Third European survey of working conditions (Paoli \& Merllié, 2001). Health problems most often reported by the workers were back pain (33\%) and thereafter occupational stress (28\%). A considerable amount of research has been devoted to how people cope when confronted with stressful situations (cf. Tamres, Janicki \& Helgeson, 2002). Coping has been defined as the cognitive and behavioral efforts to manage demands that tax or exceed the resources of the person (Lazarus \& Folkman, 1984).

\footnotetext{
${ }^{1}$ Address correspondence to Eva Torkelson, Department of Psychology, P.O. Box 213, SE-221 00 Lund, Sweden or e-mail (eva.torkelson@psychology.lu.se)

2 This study was financed by Swedish Council for Working Life and Social Research.
} 
When it comes to different coping strategies a distinction is made between problemfocused and emotion-focused strategies. The function of problem-focused strategies is to modify or eliminate the source of stress, whereas the emotion-focused strategies attempt to regulate the emotional responses elicited by the situation. Some researchers use the categories of approach and avoidance coping (Soderstrom, Dolbier, Leiferman \& Steinhardt, 2000), but the distinction between problem- and emotion-focused coping is the one most commonly used when comparisons are made between women and men (Tamres et al., 2002). Women tend to use emotion-focused strategies such as venting, avoidance and social network (Carver, Scheier \& Weintraub, 1989; Hurst \& Hurst, 1997; Muhonen \& Torkelson, 2001), whereas men are more inclined to use active problem-focused coping strategies (Ptacek, Smith \& Dodge, 1994; Hurst \& Hurst, 1997).

Several researchers maintain that there has not been enough emphasis on the issue of power and influence when gender differences in stress and coping have been studied in previous research (Banyard \& Graham-Bermann, 1993; Long \& Cox, 2000). The main focus has been on the individual, while the influence of the social context has been neglected. Yet the social contexts have a strong influence on the appraisal of a stressful situation, as well as on the appraisal of available coping strategies.

The majority of women have jobs that are characterized by limited autonomy and limited resources, e.g. low pay, inflexibility, low status and lack of career development opportunities (Alexanderson \& Östlin, 2001; Long \& Cox, 2000), which in turn can restrict women's possibilities to cope (Long \& Cox, 2000; Matud, 2004). Due to women's subordinate position in the labor market, as well as in society as a whole, it can be argued that so-called gender differences in behavior can be accounted for by differences in access to power between women and men. There are also several studies that support this notion, showing that when education, occupation and position in the organization are controlled for, few gender differences in coping can be found (Greenglass, 2002). Some studies have shown no gender differences in coping at the managerial level (McDonald \& Korabik, 1991; Torkelson \& Muhonen, 2004), whereas traditionally conceived coping patterns prevailed at the non-managerial level (Torkelson \& Muhonen, 2004).

There is a growing body of critique against the individualistic perspective that has dominated previous stress and coping research (Banyard \& Graham-Bermann, 1993; Hobfoll, Dunahoo, Ben-Porath \& Monnier, 1994; Long \& Cox, 2000; Mickelson, Lyons, Sullivan \& Coyne, 2001). Individualistic models tend to ignore the collective aspects of coping and view the individual as more or less isolated from his or her social context. There is a need to move beyond the individualistic models towards a more complex analysis that also includes the interpersonal context where coping occurs (Handy, 1995). Earlier work questioning the individualistic coping models has been conducted at Kent State University by Hobfoll et al. (1994), Mickelson et al. (2001), and Hobfoll, Geller and Dunahoo (2003). Hobfoll et al. (2003) have developed the multiaxial model of coping and a questionnaire (SACS - Strategic Approach to Coping Scale) to assess the different dimensions of the model, i.e. social-antisocial, activepassive and direct-indirect strategies (Hobfoll et al., 1994). Hobfoll et al. (2003) use the term communal coping, whereas we prefer to use the term collective coping. Collective coping can be defined as using shared or collaborative strategies in order to cope with a stressful situation (Mickelson et al., 2001). Hobfoll et al. (2003) argue that as the 
models of coping have been based on individualism, other strategies which women might be more likely to use are never measured.

In the present study coping was viewed as both an individualistic and a collective phenomenon. The aim of the investigation was to study how the use of collective and individualistic coping strategies was related to gender and organizational level. We expected that women would more often use collective coping strategies, whereas men would use problem-focused individualistic strategies to a greater extent. Further, we wanted to investigate whether non-managers used collective strategies more often than managers, both in the group as whole, and among women and men separately.

\section{METHOD}

\section{Procedure}

Data were collected by means of an Internet-based questionnaire. A covering letter including the link to the web questionnaire was sent by e-mail to 1345 female and male employees at both managerial and non-managerial level working in a Swedish telecom company. Two reminders were sent by e-mail to the participants, and the final response rate was $71 \%$.

\section{Participants}

The total number of participants was 950, of which 502 were women (82 managers, 407 non-managers and 13 had not specified their position) and 448 were men (89 managers, 357 non-managers and two had not specified their position). The mean age of the participants was 47 years, most of them were married (76\%) and worked fulltime (91\%). The participants had been working in the company for about 24 years. Only $28 \%$ of the participants had children younger than 12 years living at home. A minority (15\%) had university education. Men had university education and worked full-time to a greater extent than women. Besides the foregoing, there were no gender differences concerning the background variables.

\section{Measures}

The demographic questions included gender, age, marital status $(1=$ married/cohabiting or $0=$ single), number of children living at home and younger than 12 years, education $(1=$ university degree or $0=$ not $)$, working hours $(1=$ full-time, $0=$ part-time), length of employment and organizational level $(1=$ managerial position or 0 $=$ not $)$.

Individualistic coping was assessed by means of four different scales from the Swedish version (Muhonen \& Torkelson, 2001) of the COPE inventory (Carver et al., 1989). Two scales - active coping and positive reinterpretation and growth - were considered to measure different aspects of problem-focused coping. Active coping includes taking direct action in order to deal with the problem (e.g. "I take additional action to try to get rid of the problem"). Positive reinterpretation and growth involves efforts to construe the stressful situation in a positive way (e.g. "I try to grow as a person as a result of the experience”). Another two scales - acceptance and focus on and venting of emotions - assessed dimensions of emotion-focused coping. Acceptance implies simply accepting the situation (e.g. "I learn to live with it"). Focus on and venting of emotions denotes attempts to focus on the distress caused by the situation 
and ventilate feelings evoked by it (e.g. "I get upset and let my emotions out". Participants were asked to indicate what they usually did when they were under considerable stress at work. Response alternatives ranged from 1 (= I usually don't do this at all) to 4 (= I usually do this a lot). The reliability coefficients for the individualistic coping scales ranged from $\alpha=.68$ to $\alpha=.72$.

Collective coping was assessed by two scales from COPE inventory (seeking social support for instrumental reasons and seeking social support for emotional reasons) and one scale (social joining) from SACS - Strategic Approach to Coping Scale (Hobfoll et al., 1994). Seeking social support for instrumental reasons includes seeking advice, assistance or information (e.g. "I ask people who had similar experiences what they did"). Seeking emotional social support contains getting sympathy and understanding (e.g. "I talk to someone about how I feel”). Social joining stands for joining with others and considering others' feelings and wishes (e.g. "Join together with others to deal with the situation together"). All the coping scales consisted of four items each, except social joining which contains five items. Participants were asked to indicate what they usually did when they were under considerable stress at work. Response alternatives ranged from 1 (I usually don't do this at all) to 4 (I usually do this a lot). The reliability coefficients for the collective coping scales ranged from $\alpha$ $=.68$ to $\alpha=.73$.

\section{RESULTS}

Table 1 shows the results of MANOVAs testing differences in coping related to gender and organizational level. The men did not use the problem-focused individualistic coping strategies (active coping and positive reinterpretation) more frequently than women did. On the contrary, women engaged more in positive reinterpretation than men. In addition, women used focus on and venting of emotions to a greater extent than men, and were more prone to use all the studied collective strategies - seeking emotional and instrumental social support and participating in social joining - than men were.

\section{Table 1 about here}

When it comes to comparisons between different organizational levels, the results showed several significant differences concerning both the individualistic and the collective strategies. The managers more often used the problem-focused individualistic strategies, active coping and positive reinterpretation, whereas the non-managers used more often the emotion-focused individualistic strategy of acceptance. The nonmanagers did not employ collective strategies more frequently than managers. Instead the managers were more likely to use all of the three dimensions of collective coping: seeking emotional and instrumental social support and participating in social joining. There was no interaction effect between gender and organizational level.

In order to capture the variation among women and men we wanted to examine whether there were differences in coping between organizational levels when women and men were analysed separately. The results of ANOVAs in Table 2 indicate that approximately the same pattern appeared for women and men. Both women and men at the managerial level used more of the two problem-focused individualistic strategies, 
active coping and positive reinterpretation. Female and male managers also sought instrumental social support and social joining to a greater extent than non-managers. Female non-managers employed acceptance as a coping strategy more often than female managers did. Male non-managers did not use any of the coping strategies to a greater extent than male managers.

Table 2 about here

\section{DISCUSSION}

The aim of the present study was to investigate how the use of collective and individualistic coping strategies was related to gender and organizational level among female and male employees at both managerial and non-managerial level in a Swedish telecom company. Based on earlier studies we expected women to use collective coping strategies more often, and men to use problem-focused individualistic strategies to a greater extent. Of further interest was to compare non-managers and managers in order to investigate how the hierarchical level was related to coping among both women and men.

Contrary to earlier studies (Ptacek, Smith \& Dodge, 1994; Hurst \& Hurst, 1997), men did not use the problem-focused individualistic coping strategies (active coping and positive reinterpretation) more frequently than women did. It was instead the women that were more engaged in the individualistic coping strategy positive reinterpretation than men. Further, in line with earlier studies (Carver et al., 1989; Hurst \& Hurst, 1997; Muhonen \& Torkelson, 2001), women employed the individualistic emotion-focused strategy focus on and venting of emotions to a greater extent than men.

The results also showed that women more often than men used the studied collective coping strategies: seeking emotional and instrumental social support and social joining. Several differences in coping were found between female and male managers, unlike other studies that have been conducted at the managerial level (McDonald \& Korabik, 1991). One reason might be that female and male managers' work situations were not comparable even though they were at the same organizational level. It is also possible that a larger proportion of the women were at a lower managerial level than men, and this might explain the differences in coping.

Significant differences in the use of the individualistic and collective coping strategies could be found between the different organizational (hierarchical) levels. When it comes to individualistic coping the managers more often used the problemfocused strategies of active coping and positive reinterpretation, whereas the nonmanagers more often used the emotion-focused strategy of acceptance. Managers were more likely than the non-managers to utilize all three dimensions of collective coping: seeking emotional and instrumental social support and participating in social joining.

Studies comparing women and men run a risk of engaging in simple categorization and consequently emphasize essential gender differences while overlooking the withingroup differences (Banyard \& Graham-Bermann, 1993). In order to avoid viewing gender only as a variable, or "engaging in body-counting” (Alvesson \& Billing, 2002), we also wanted to analyze coping among women and men separately and in that way capture the variation among women and men. The results showed approximately the 
same pattern for both women and men. Managers, both women and men, more often employed the problem-focused individualistic strategies, active coping and positive reinterpretation. This result supports the idea that the work situation influences employees' possibilities to cope (Long \& Cox, 2000; Matud, 2004). Employees who are higher up in the organizational hierarchy can have access to problem-focused strategies to a greater extent than employees at the lower levels. The results also showed that female managers used the collective strategies of seeking instrumental social support and social joining to a greater extent than female non-managers. The same pattern applied to male managers and non-managers as well. This unexpected finding indicates that the collective strategies might have been underestimated in earlier research with an individualistic focus (Banyard \& Graham-Bermann, 1993; Long \& Cox, 2000; Hobfoll et al., 2003; Mickelson, 2001). The only strategy that the women at the non-managerial level used more than women at the managerial level was acceptance, an individualistic emotion-focused strategy that is considered a less effective way of coping (Billings \& Moos, 1981). Male non-managers did not use any of the coping strategies more often than the male managers.

The findings of the study have some limitations. First, the variables were measured by self-reports, which can lead to inflated correlations attributed to common method variance. Another limitation is the cross-sectional design of the study, which does not allow causal conclusions to be drawn on the basis of the results. Finally, the sample consisted of a specific group of employees, and one should therefore be cautious in generalizing the results beyond the study.

In sum, the results of the study showed differences in coping related to both gender and organizational level. Women used more often collective strategies, but so too did managers, both women and men. Separate analyses for women and men showed similar patterns, indicating the importance of organizational level for coping. Additional studies are needed in order to investigate the meaning of collective coping at work for women and men at different organizational levels. There is also a need to further develop the assessment of collective coping beyond self-reports. In addition, it would be interesting to investigate the use of individualistic and collective coping strategies among people in individual and collective societal cultures.

\section{REFERENCES}

ALVESSON, M., \& BILLING, Y. DUE (2002) Beyond body-counting. A discussion of the social construction of gender at work. In I. Aaltio \& A. J. Mills (Eds.), Gender, identity and the culture of organizations (pp. 72-91). London: Routledge.

BANYARD, V., \& GRAHAM-BERMANN, S. A. (1993) Can women cope? A gender analysis of theories of coping with stress. Psychology of Women Quarterly, 17, 303-318.

BILLINGS, A. G., \& MOOS, R. H. (1981) The role of coping responses and social resources in attenuating the stress of life events. Journal of Behavioral Medicine, 4, 139-157.

CARVER, C. S. SCHEIER, M. F., \& WEINTRAUB, J. K. (1989) Assessing coping strategies: A theoretically based approach. Journal of Personality and Social Psychology, 56, 267-283. 
GREENGLASS, E. R. (2002) Work stress, coping, and social support: Implications for women's occupational well-being. In D. L. Nelson \& R. J. Burke (Eds.), Gender, work stress, and health (pp. 85-96). Washington, DC: American Psychological Association.

HANDY, J. (1995) Rethinking Stress: Seeing the Collective. In T. Newton, J. Handy \& S. Fineman (Eds.), Managing Stress: Emotion and power at work (pp. 85-96). London: Sage.

HOBFOLL, S. E. DUNAHOO, C. BEN-PORATH, Y., \& MONNIER, J. (1994) Gender and coping: The dual axis model of coping. American Journal of Community Psychology, 22, 49-82.

HOBFOLL, S. E., GELLER, P., \& DUNAHOO, C. (2003) Women's coping: Communal versus individualistic orientation. In M. J. Schabracq, J. A. M. Winnubst \& C. L. Cooper (Eds.), Handbook of work and health psychology (pp. 237-257). Chichester: John Wiley \& Sons Ltd.

HURST, T. E., \& HURST, M. H. (1997) Gender differences in mediation of severe occupational stress among correctional officers. American Journal of Criminal Justice, 22, 121-137.

LAZARUS, R. S., \& FOLKMAN, S. (1984) Stress, appraisal, and coping. New York: Springer Publishing Company.

LONG, B. C., \& COX, R. S. (2000) Women's ways of coping with employment stress: a feminist contextual analysis. In P. Dewe, M. Leiter \& T. Cox (Eds.), Coping, Health and Organizations (pp. 109-123). London: Taylor \& Francis.

MATUD, M. P. (2004) Gender differences in stress and coping styles. Personality and Individual Differences, 37, 1401-1415.

MCDONALD, L. M., \& KORABIK, K. (1991) Sources of stress and ways of coping among male and female managers. In P. L. Perrewé (Ed.), Handbook on job stress [Special Issue]. Journal of Social Behavior and Personality, 6, 185-198.

MICKELSON, K. D., LYONS, R. F., SULLIVAN, M. J. L., \& COYNE, J. C. (2001) Yours, Mine, Ours: The relational context of communal coping. In B. R. Sarason \& S. Duck (Eds.), Personal relationships: Implications for clinical and community psychology (pp. 181-200). Chichester: John Wiley \& Sons Ltd.

MUHONEN, T., \& TORKELSON, E. (2001) Swedish version of the COPE inventory. Lund Psychological Reports, 2. Department of Psychology, Lund University.

PAOLI, P., \& MERLLIÉ, D. Third European Survey on Working Conditions 2000. (2001) Luxembourg: Office for Official Publications of the European Communities. http://www.eurofound.eu.int/publications/files/EF0121EN.pdf

PTACEK, J. T. SMITH, R. E, \& DODGE, K. L. (1994) Gender differences in coping with stress: When stressors and appraisals do not differ. Personality and Social Psychology Bulletin, 20, 421-430.

SODERSTROM, M. DOLBIER, C. LEIFERMAN, J., \& STEINHARDT, M. (2000) The relationship of hardiness, coping strategies, and perceived stress to symptoms of illness. Journal of Behavioral Medicine, 23, 311-328.

TAMRES, L. K. JANICKI, D., \& HELGESON, V. S. (2002) Sex differences in coping behavior: a meta-analytic review and an examination of relative coping. Personality and Social Psychology Review, 6, 2-30.

TORKELSON, E., \& MUHONEN, T. (2004) The role of gender and job level in coping with occupational stress. Work \& Stress, 18, 267-274. 
TABLE 1

F-TESTS FOR GENDER AND ORGANIZATIONAL LEVEL (MANAGER/NON-MANAGER) DIFFERENCES IN COPING VARIABLES

\begin{tabular}{|c|c|c|c|c|c|c|c|}
\hline \multirow[b]{2}{*}{ Coping } & \multirow{2}{*}{$\begin{array}{r}\text { Women } \\
(n=475)\end{array}$} & \multirow{2}{*}{$\begin{array}{r}\text { Men } \\
(n=436) \\
\end{array}$} & \multirow{2}{*}{$\begin{array}{r}\text { Managers } \\
(n=167) \\
\end{array}$} & \multirow{2}{*}{$\begin{array}{r}\text { Non-managers } \\
(n=744)\end{array}$} & \multicolumn{3}{|c|}{ F-test/significances } \\
\hline & & & & & Gender & Org. level & Interactions \\
\hline \multicolumn{8}{|c|}{ Individualistic strategies } \\
\hline \multicolumn{8}{|l|}{ Active coping } \\
\hline$M$ & 12.65 & 12.56 & 13.27 & 12.46 & & & \\
\hline$S D$ & 1.84 & 1.72 & 1.60 & 1.79 & 0.36 & $29.26 * *$ & 0.40 \\
\hline \multicolumn{8}{|c|}{ Positive reinterpretation } \\
\hline$M$ & 11.97 & 11.50 & 12.85 & 11.50 & & & \\
\hline$S D$ & 1.94 & 2.02 & 1.65 & 1.97 & $6.29 *$ & $71.51 * *$ & 0.85 \\
\hline \multicolumn{8}{|l|}{ Acceptance } \\
\hline M & 10.61 & 10.45 & 10.10 & 10.63 & & & \\
\hline$S D$ & 2.13 & 2.18 & 2.27 & 2.12 & 0.52 & $8.24 * *$ & 0.01 \\
\hline \multicolumn{8}{|c|}{ Venting of emotions } \\
\hline$M$ & 9.06 & 8.05 & 8.26 & 8.65 & & & \\
\hline$S D$ & 2.08 & 2.24 & 2.00 & 2.26 & $25.93^{* *}$ & 3.58 & 0.19 \\
\hline \multicolumn{8}{|l|}{ Collective strategies } \\
\hline \multicolumn{8}{|c|}{ Seek instrumental support } \\
\hline$M$ & 11.54 & 10.53 & 11.66 & 10.92 & & & \\
\hline$S D$ & 1.97 & 2.10 & 1.75 & 2.14 & $29.89 * *$ & $20.44 * *$ & 0.69 \\
\hline \multicolumn{8}{|c|}{ Seek emotional support } \\
\hline$M$ & 10.34 & 8.45 & 9.70 & 9.38 & & & \\
\hline$S D$ & 2.37 & 2.23 & 2.37 & 2.51 & $86.64 * *$ & $4.20 *$ & 0.27 \\
\hline \multicolumn{8}{|l|}{ Social joining } \\
\hline$M$ & 14.44 & 13.35 & 14.66 & 13.75 & & & \\
\hline$S D$ & 2.16 & 2.19 & 1.69 & 2.31 & $29.98 * *$ & $27.19 * *$ & 0.97 \\
\hline
\end{tabular}


TABLE 2

F-TESTS FOR DIFFERENCES BETWEEN ORGANIZATIONAL LEVELS CONCERNING COPING FOR WOMEN AND MEN

\begin{tabular}{|c|c|c|c|c|c|c|}
\hline \multirow[b]{3}{*}{ Coping } & \multicolumn{2}{|c|}{ Women } & \multicolumn{4}{|c|}{ Men } \\
\hline & \multicolumn{2}{|r|}{ Non- } & \multirow[b]{2}{*}{$\begin{array}{c}\text { F-test/ } \\
\text { significances }\end{array}$} & \multicolumn{2}{|r|}{ Non- } & \multirow[b]{2}{*}{$\begin{array}{c}\text { F-test/ } \\
\text { significances }\end{array}$} \\
\hline & $\begin{array}{c}\text { Managers } \\
(n=82)\end{array}$ & $\begin{array}{l}\text { managers } \\
(n=400)\end{array}$ & & $\begin{array}{c}\text { Managers } \\
(n=85)\end{array}$ & $\begin{array}{l}\text { managers } \\
(n=355)\end{array}$ & \\
\hline \multicolumn{7}{|c|}{ Individualistic strategies } \\
\hline \multicolumn{7}{|c|}{ Active coping } \\
\hline$M$ & 13.29 & 12.50 & & 13.20 & 12.37 & \\
\hline$S D$ & 1.66 & 1.84 & $13.00 * *$ & 1.58 & 1.77 & $15.85^{* *}$ \\
\hline \multicolumn{7}{|c|}{ Positive reinterpretation } \\
\hline$M$ & 12.99 & 11.75 & & 12.72 & 11.19 & \\
\hline$S D$ & 1.64 & 1.92 & $29.70 * *$ & 1.64 & 2.00 & $43.71 * *$ \\
\hline \multicolumn{7}{|c|}{ Acceptance } \\
\hline$M$ & 10.17 & 10.72 & & 10.07 & 10.57 & \\
\hline$S D$ & 2.40 & 2.07 & $4.62 *$ & 2.14 & 2.17 & 3.75 \\
\hline \multicolumn{7}{|c|}{ Venting of emotions } \\
\hline$M$ & 8.69 & 9.12 & & 7.83 & 8.11 & \\
\hline$S D$ & 2.05 & 2.08 & 2.99 & 1.84 & 2.32 & 1.11 \\
\hline \multicolumn{7}{|c|}{ Collective strategies } \\
\hline \multicolumn{7}{|c|}{ Seek instrumental support } \\
\hline$M$ & 12.07 & 11.41 & & 11.23 & 10.35 & \\
\hline$S D$ & 1.73 & 2.00 & $7.64^{* *}$ & 1.71 & 2.15 & $12.62 * *$ \\
\hline \multicolumn{7}{|c|}{ Seek emotional support } \\
\hline$M$ & 10.57 & 10.29 & & 8.86 & 8.35 & \\
\hline$S D$ & 2.27 & 2.38 & 0.99 & 2.13 & 2.26 & 3.64 \\
\hline \multicolumn{7}{|c|}{ Social joining } \\
\hline$M$ & 15.09 & 14.31 & & 14.26 & 13.12 & \\
\hline$S D$ & 1.78 & 2.19 & $8.90 * *$ & 1.50 & 2.29 & $19.39 * *$ \\
\hline
\end{tabular}

